\title{
Mundos na ponta do lápis: desenhos de crianças pequenas ou de como estranhar o familiar quando o assunto é criação infantil
}

\author{
Marcia Aparecida Gobbi \\ Universidade de São Paulo
}

\section{Resumo}

Frequentemente naturalizados, os desenhos infantis constituem complexas relações que dependem de características sociais, históricas, culturais e econômicas de seus criadores. 0 estudo meticuloso sobre os desenhos criados na infância, e em especial, entre as crianças pequenas, quando compreendidos como artefatos culturais e documentos históricos, pode contribuir para se respeitar e conhecer lógicas de construção de culturas naquilo que caracteriza a infância. Tarefa que pode ser tomada pelas ciências sociais, em especial sociologia e antropologia. Desenhar é compreendido aqui como experiência de vida e um convite a ver e compreender o outro do ponto de vista cultural, histórico e social.

Palavras-chave: Desenhos. Pequena infância. Sociologia. Antropologia. 


\section{Worlds on the tip of a pencil: little children's drawings or how to be surprised by the familiar when it comes to creating}

Often treated as natural, children's drawings are complex relationships depending on the social, historical, cultural and economic conditions of their creators. A careful study of childhood, especially early childhood, drawings, understood as cultural artifacts and historical documents, can contribute towards respect and understanding of the logics of the culture building that characterizes childhood. This task can be undertaken by the social sciences, especially sociology and anthropology. Drawing is understood here as life experience, and an invitation to see and understand the other, from the cultural, historical and social points of view.

Keywords: Drawings. Early childhood. Sociology. Anthropology.

\section{Mundos en punta de lápiz: dibujos de niños pequeños o como sorprender al familiar cuando se trata de creaciones infantiles}

A menudo naturalizados, como resultado de los estudios sobre el desarrollo infantil, los dibujos de los niños son relaciones complejas en función de las condiciones sociales, históricas, culturales y económicas de sus creadores. Un estudio cuidadoso de los dibujos infantiles, entendidos como artefactos culturales y documentos históricos, puede contribuir al respeto y a la comprensión de la lógica de las culturas de construcción que caracteriza a la infancia. Esta tarea debe ser realizada por las ciencias sociales, especialmente la sociología y la antropología, y otras contribuciones que incluso pueden contrarrestar los estudios de la psicología, que se mantienen con el tiempo. El dibujo se entiende aquí como una experiencia de vida y una invitación a ver y entender el punto de vista cultural, histórico y social del otro.

Palabras clave: Dibujos. Niños pequeños. Sociología. Antropología. 
Num dia de inverno em 1882, voltando da Certosa di Bologna, fui forçado por uma chuva a reparar no pórtico que conduz ao Meloncello. Eu não sabia que sob aqueles arcos se encontrava uma exposição literária e artística permanente. Com pouco valor estético, se assim queremos pensar, e também um pouco tímida, largamente ornada de modéstia, rara para os tempos que correm.

Poucos trabalhos têm a assinatura do autor, o que se deverá sempre lamentar, pois se constitui como grande lacuna na história da arte e da literatura italiana.

(...) As obras dos desenhistas menores, as quais se encontram situadas naturalmente mais abaixo, mostram-se com técnica e lógica menores, superam, porém, todas as outras no decoro. Além disso, (necessário nota a título de louvor) se iguala consideravelmente a traços poéticos!

A tristeza do dia, do lugar e da alma, que mal comportava as epigramas daqueles que haviam trabalhado na zona superior, me conciliaram com a arte ingênua das crianças e me sugeriram a ideia deste estudo.

Corrado Ricci, L'arte Dei Bambini

Itália, passagem de 1882 para 1883. Corrado Ricci estudioso do desenho infantil, ao caminhar pelas ruas, num dia chuvoso, deparou-se com traçados feitos por crianças e deixados como marcas nas paredes no interior dos pórticos presentes na cidade de Bolonha ${ }^{2}$. A partir desse encontro com ares de descoberta de linhas e formas que, em certa medida, reclamaram por seus olhares mais atentos e curiosos, Ricci passou a interessar-se de modo rigoroso pelos desenhos como forma de expressão infantil e, em especial, ao que tudo indica em seus escritos, aqueles elaborados pelas crianças pequenas. Tratavam-se de inscrições deixadas nas paredes pelas meninas e meninos, tais como os atuais grafites popularizados pela juventude urbana. Mas, o que havia nessa expressiva manifestação infantil que o tomou no desejo por conhecer mais profundamente a infância e seus traçados, ou o desenho infantil, como já se convencionou chamar? Marcas de infância reveladas numa produção de inscrições anônimas que chamavam a atenção do passante que, até então, não atinava para tais expressões infantis, pego de surpresa e desavisado, vê o que até então não havia visto. Estranha. Espanta-se.

0 espanto indica certo desconhecimento sobre inventividade infantil, ao mesmo tempo em que denota encantamento com a descoberta de suas capacidades. Reconhecimento esse que implica a tomada de postura favorável à infância e suas inventividades presentes em variados traçados. 
Corrado Ricci, o homem que foi surpreendido pelos desenhos elaborados por meninas e meninos e deixados como marcas pessoais nos muros bolonheses, destaca-se por encontrar-se entre os primeiros entusiastas do desenho infantil. Em seu estudo sobre desenho de crianças, iniciado desde essa primeira descoberta e publicado em 1887, buscava conhecer princípios de uma arte infantil e com isso os desenhos das crianças chamavam-lhe a atenção sendo depositários de conceitos que envolviam as pesquisas desse estudioso.

Não se trata aqui de recuperar e apresentar a gênese dos estudos sobre desenho infantil. As crianças desenham há tempos, sobre variados suportes e isso tem despertado a atenção de pesquisadores oriundos de diferentes áreas de conhecimento. Quase século e meio após essas primeiras descobertas e interesses iniciais pelos desenhos criados pelas crianças, essas manifestações expressivas ainda chamam a atenção por diferentes motivos: beleza, concepção estética infantil, experiências e experimentos com distintos materiais, formas de mensurar e conhecer a capacidade cognitiva das crianças e, por que não, emoções e impressões sobre distintos acontecimentos históricos e sociais, expressão da imaginação infantil? Com isso, têm-se configurado como fonte de interesse de críticos de arte, pedagogos, filósofos, psiquiatras, antropólogos, pediatras, psicólogos, sociólogos e antropólogos. Os desenhos das crianças instigam-nos, é sabido, e são várias as contribuições dessas distintas áreas e seus pesquisadores.

Inicialmente Ricci surpreendeu-se pela qualidade estética apresentada nos desenhos das crianças. A chamada arte infantil foi associada a certa capacidade espontânea das crianças em desenvolver seus desenhos. Encontrava-se, contudo, a perspectiva de uma infância essencialista levando à compreensão de continuidade natural do desenvolvimento das crianças e, consequentemente, seus desenhos. Trata-se de concepções segundo as quais os desenhos passavam naturalmente por etapas de desenvolvimento, em certa medida previsíveis, de acordo com faixas etárias. Esse modo de conceber as criações infantis impregnou modos de ver e se relacionar com as crianças e seus desenhos, sobretudo quando elaborados por meninos e meninas com bem pouca idade. Há que sublinhar que essa forma de compreensão pode levar à perda de oportunidade de entendê-los a partir e em diálogo com outros campos teóricos, sobretudo aqueles que se propõem a observar tais manifestações expressivas do ponto de vista cultural, o que levaria a certo estranhamento. Pode se supor que, de tanto ver, banalizamos o que é visto. É possível afirmar que os desenhos das crianças, não são feitos apenas para ser observados como obras independentes. Ao observarmos com cautela, perceberemos que os mesmos compõem certos rituais infantis, demonstram e criam hierarquias entre os desenhistas e seus desenhos passam a ter valores 
e são vistos de maneiras diversas entre os pares de idades iguais ou diferentes, recebem tratamentos diferenciados de acordo com o lugar ocupado entre os demais desenhos e seus autores. Impactam relações e espaços, criam ambientes. Há complexidade e riqueza de práticas em torno do desenho e do ato de desenhar que exigem olhares curiosos que extrapolam o papel e retornam a ele de modo dinâmico, o que pode suscitar diferentes leituras e compreensões ao longo do tempo.

Há que manter-se atento, pois a forte presença de desenhos infantis entre nós expõe uma questão fundamental: corremos o risco de naturalizá-los e passar a vê-los ainda menos, ou melhor, com menos cautela e curiosidade. Tão abundantes cotidianamente tornam-se pouco conhecidos. Trata-se de algo perverso em relação à infância e as criações infantis, voltando-se contra o valor existente no desenho e as relações que podem ser estabelecidas a partir de sua participação cotidiana em nossas vidas. Várias são as situações em que podemos olhar para distintos assuntos desenhados pelas crianças. Eles estão em pequenos ou grandes suportes e de variados materiais, em muros ou paredes de casas ou escolas, pontos de ônibus, nos são ofertados pelas crianças em diversas ocasiões, enfim, povoam a vida em suas variadas dimensões. Essa profusão de situações em que nos encontramos com essa expressiva manifestação infantil, por vezes, obsta a compreensão em sua inteireza. A rapidez do tempo furta e tem fragilizado nossa capacidade de ver impedindo-nos de sorver e alcançar o que os traçados apresentam e representam. Misturam-se entre tantos outros artefatos culturais criados por meninos e meninas e passam despercebidos como manifestação da infância. Salvo exceções, raramente nos ocorre que resultam de complexas relações dependendo das características sociais, históricas, culturais e econômicas de seus criadores que podem ser definidos também como pesquisas pessoais das crianças.

Sabe-se que a compreensão dos desenhos é culturalmente orientada; o olho é socialmente educado, vendo o que, grosso modo, aprende a ver. Pensar em desenhos implica questionar o que se vê, quando e como. 0 olhar não é isento ou neutro. $E$, nesse sentido, vale a ressalva de que é preciso desnaturalizar nosso modo de ver e compreender o que desenhos de crianças de todas as idades nos apresentam sem esquecer-se daqueles criados pelas bem pequenas.

0 estudo meticuloso sobre os desenhos criados na infância, quando estes são compreendidos como artefatos culturais e documentos históricos, pode contribuir para se respeitar e conhecer lógicas de construção de culturas naquilo que caracteriza a infância. Trata-se de tarefa que pode ser tomada pelas ciências sociais, em especial Sociologia e Antropologia, apresentando fecundas contribuições que podem contrapor e problematizar certos aspectos relativos aos estudos oriundos 
da psicologia, preponderantes ao longo de tempos. Quando se volta para questões relativas às investigações sobre meninas e meninos, essa tarefa torna-se crucial, uma vez que o estudo dos desenhos pode servir como forma de reconhecer e significar a própria infância, e, de modo concomitante, ao adulto e adulta que se debruçam em pesquisas sobre essa manifestação expressiva infantil. 0 desenho vincula representação e apropriação do outro enquanto se desenha, ao mesmo tempo em que toma para si, constrói e demonstra de diversos modos, diferentes culturas e as próprias culturas infantis com suas especificidades.

Desenhar, como já mencionado, é compreendido aqui como um exercício cotidiano de vida em que desenhar pode prover a existência, a descoberta e a invenção de mundos. Enseja modos e maneiras de ver, apropriar-se e elaborar coisas. Deste modo, artefato que apresenta formas e narrativas particulares. Orientam outras lógicas quando passam a circular entre nós. Efêmeros, também os desenhos evidenciam rejeição à rapidez, ao mesmo tempo em que a aceitam sob forma de captura e registro. Ao desenhar, não apenas experimentamos o ato do desenho em si, como também a experiência de ver. Desenhar é, de certa forma, ver. Materializar o que é visto com todos os sentidos e a partir das relações com o outro. Apropriar-se do outro pelo lápis, caneta, giz, carvão independente da faixa etária de quem desenha.

Nesse ensaio pretende-se abordar os desenhos das crianças em sua relação com estudos da infância apresentando reflexões que consideram o desenho numa perspectiva ampla, qual seja, o diálogo entre os campos da sociologia e antropologia com estudos da educação em abordagens historiográficas. Vale sublinhar que os estudos sobre desenhos, ou que os compreendem como auxiliares em pesquisas etnográficas, ainda desconsideram - com poucas exceções - as crianças em idade até cinco ou seis anos, o que leva à naturalização da ideia de ausência e de falta quando se pensa em coleta e modos de compreender os desenhos nas pesquisas. Algo preocupante, uma vez que a ampliação das formas de compreendê-los levaria a ganhos no que concerne ao entendimento da própria infância e seus artefatos no âmbito da cultura material produzida pelas crianças.

Esse ensaio procura contribuir com os estudos da infância apresentando desenhos de meninos e meninas, criação presente em nossas vidas, ao mesmo tempo alijada do cotidiano, sobretudo quando compreendida em seu caráter social e cultural como evidências de culturas e como fomentadoras de construções culturais numa expectativa de participação infantil em contextos sociais, desde tenra idade. É o encontro entre educação, ciências sociais, em especial a Sociologia, infâncias e seus desenhos que será desenvolvido e celebrado aqui dentro dos limites deste ensaio. Pretende-se partir desses campos e propor reflexões sobre a potencialidade dos desenhos de crianças pequenas em relação às práticas 
culturais e de construção de cultura da e na infância, em destaque, das meninas e meninos com até cinco anos de idade. Com isso, não se apresenta a realidade nos desenhos, mas, como representações que são, procura-se a possibilidade de discutir sobre diversas maneiras de ver e registrar mundos. Ainda, considerando os desenhos como documentos e artefatos da cultura, objetiva-se perceber lógicas infantis e a reorientação das mesmas diante e em relação com o ato de desenhar e os resultados obtidos com o desenho. Mundos são criados, negociações são abertas. Um convite a ver e debater é feito a todos.

\section{Outra maneira de falar e mostrar sociedades: Desenhos de meninas e meninos como documentos históricos e artefatos culturais}

Por tempos reduzimos nosso entendimento sobre os desenhos das crianças à compreensão de que eles expõem basicamente aspectos cognitivos e referentes ao desenvolvimento psíquico infantil. Comisso, desconsideram-se elementos culturais e sociais de seus criadores ou evidências das culturas infantis propriamente ditas que podem encontrar-se presentes entre os traçados elaborados pelas meninas e meninos. Além de engessarem nossa capacidade compreensiva, essa expectativa faz valer entendimentos que destituem a autoria de quem os elaborou como sujeitos situados histórica e socialmente. Preponderaram perspectivas etapistas ou evolucionistas sabidamente bastante refutáveis e passíveis de problematizações, como se o desenho infantil passasse obrigatoriamente por estágios em seu desenvolvimento. Nelas desconsideram-se aspectos sociais e culturais que envolvem não somente a feitura do desenho como seu resultado e, com isso, pode-se negligenciar as próprias crianças e suas origens de classe social, étnicas e de gênero.

Contudo, grande contribuição encontra-se em considerar os desenhos como discursos autorizados a substituir ou alternar sistemas culturais ou históricos estabelecidos e questionar "a" história ou culturas tidas como oficiais ou superiores, tal como aquelas de adultos em relação às manifestas pelas crianças. Trata-se de compreender outra maneira de falar e representar a sociedade, neste caso, do lugar das crianças, mudando o ângulo de visão e compreensão do mundo. É empreender esforços por contrariar o anonimato imposto à infância, em especial de crianças bem pequenas. 0 desenho, quando visto com rigor e cuidado, implica conhecer aquele que o fez, as narrativas apresentadas e suas lógicas.

Os desenhos elaborados pelas crianças permitem-nos conhecer, entre outras coisas, elementos da sociedade em geral, o que envolve interpretações e representações, por vezes, de tipos particulares de seus criadores, sem esquecer- 
se que elas estão pautadas também em sua capacidade. Os desenhos apresentam marcantes e inventivas maneiras de expor diferentes assuntos que documentam o cotidiano. Entre os traçados percebem-se certos temas, cores, formas de uso de materiais, jeitos de organização espacial dos suportes desenhados, ou ainda, de registrar modos de compreender ou explicar diferentes contextos em que estão inseridas ou em que colaboram para sua elaboração e construção cultural. 0 fato de terem sido criados sem a intenção documental não os destituem do peso histórico e não os livram de documentar e guardar memórias de infância e seus conhecimentos sobre diversos contextos sociais e culturais. Encontra-se neles ricos e complexos processos de elaboração do presente e do passado, também de inventar, apresentar e projetar mundos. Por que não? Há que estar atento. "Os objectos existem perante os olhos que os olham e cada olhar tem a sua própria história, feita de construção intelectual, experiência, sensibilidade e do próprio devaneio em que procura os seus limites." (Joaquim Pais de Brito, p. 14, 2009)

Porém, ver é um exercício desafiante e difícil, ao qual não somos iniciados. Infelizmente, temos uma história que nos marca com limites para ver e compreender a partir de diferentes linguagens e sentidos, assim como, temos em nossa origem histórias de desconsideração da linguagem do desenho que marcam nossa trajetória de vida. Desse modo, encontram-se longe de nossos hábitos diários, tanto o fazer desenhos como vê-los com vagar. Apenas olhamos rapidamente tudo ao redor, quando muito. Ver desenhos envolve códigos peculiares que, por vezes, os coadunam a outras linguagens das crianças. Impõe rigor e sensibilidade quanto à observação dos elementos contidos sobre a superfície desenhada. Em suma, enredar-se ao objeto, que de modo intrínseco pode gerar curiosidades, perscrutando-o naquilo que possibilita de questionamentos e respostas ao pesquisador e ao próprio objeto.

O desenho, em diferentes espaços, institucionais ou não, é considerado uma prática social, portanto, suporte de representações sociais que podemos conhecer, não as considerando como retratos da realidade. Como instrumento, permite conhecer melhor aquilo que a criança desenhista é, bem como, à própria criança saber mais sobre os outros de idades iguais e diferentes que com ela se relacionam, de perto e de longe descobrindo a si mesmas e ao mundo conjuntamente.

Ao tratar os desenhos criados pelas crianças, desde bem pequenas, como artefato cultural ou fonte documental, não significa que possam ser vistos como cópias da realidade, equívoco ainda muito cometido. Como verdade iconográfica, não é expressão de neutralidade ou do todo ali representado. É invenção, fantasia, guarda elementos da imaginação e, por que não do cotidiano vivido e sentido pelas meninas e meninos? É um fragmento bom para pensar sobre diferentes questões teóricas e práticas referentes às dinâmicas sociais, envolvendo ou não crianças, 
mas que seguramente podem partir delas.

É curioso e, por vezes, prazeroso observar as crianças desenhando, criando, esboçando danças sobre o papel, em que seus corpos são movidos a deixar suas marcas sobre diferentes suportes, contudo, muitas vezes nos acomodamos somente com estas observações e deixamos de lado que a permanência deste instante pode ganhar outros contornos. Ela documenta. Compreender as dinâmicas que envolvem 0 ato de desenhar e o desenho propriamente, implica esforçar-se por não perder as particularidades existentes nessa expressão plástica infantil. Aquilo que é fugaz - o desenho e seus suportes - e que, como tal, pode se perder rapidamente no tempo, nunca cessa, dependendo da maneira como ele é organizado, ou mesmo, registrado por seus organizadores ou coletores. Essas maneiras de nos relacionarmos com estes objetos-desenhos revelam, por sua vez, qual a concepção que se tem daquele que o criou, bem como, da própria criação.

Compreendê-los como documento histórico implica a construção de olhares rigorosos, minuciosos e práticas reflexivas sobre as relações sociais e como as crianças ordenam sua percepção de mundo e nos apresentam em seus traçados e assuntos selecionados. É problematizá-los como narrativas culturais criadas na infância pelas crianças comportando nisso a imaginação e demais elementos de suas vidas inventadas ou experienciadas cotidianamente e que contribuem com a elaboração e construção culturais numa relação clara entre distintas gerações e pessoas de mesma idade.

Numa perspectiva histórica vale perguntar: o que está guardado nos desenhos ao longo do tempo? 0 que revelam sobre as transformações do tempo, e por ele impostas? Os desenhos infantis podem levar-nos a conhecer nas imagens apresentadas a elaboração do passado em que se conjugam lembranças, esquecimentos, rejeições, desejos e, por que não, formas que recriam passados e inventam futuros? Considerando esses aspectos, Souza (2009) destaca a exposição realizada na Biblioteca Nacional da Espanha no ano de 2007 que teve como título "Apesar de todo dibujan: La Guerra Civil Espanhola vista por los niños". Trata-se de uma forma de observar modos de elaboração das crianças sobre o passado na guerra, o que por vezes, passa ao largo de nossas preocupações e conhecimento. Não caberia, nos limites e propósitos deste ensaio, maior aprofundamento sobre exposições de obras infantis, porém, cabe sublinhar que essa, entre outras, ao expor acervos de desenhos provoca a conhecer a infância a partir das crianças. Implica escapar de determinações que enrijecem nossas formas de ver situadas em concepções evolucionistas sobre a criação de desenhos. Leva a figurar concepções sociológicas e antropológicas que se voltam para compreender a qualidade e a importância das composições em si, ao mesmo tempo em que provocam a compreender a capacidade inventiva de, com os desenhos, dar a ver 
a si mesma, e alterar orientações culturais a partir de sua existência entre as crianças nos grupos sociais, modificando-as.

Como fontes documentais apresentam indícios que levam a quem quer conhecê-los, a entrar em domínios discretos ou particulares de certo jeito de ser criança aliado às complexas relações estabelecidas em seu entorno sociocultural. Elaborados por crianças inscrevem-se em estudos sobre cultura material, dialogando diretamente com investigações historiográficas e, mais que isso, modifica significativamente o caráter das concepções presentes até então, sobre desenho infantil e infância.

É interessante que consideremos a comunicação com o grupo social nos quais as crianças estão inseridas, observando que para a criança pequena, em diferentes ambientes por ela frequentados, desenhos e outras formas expressivas não estão separados do cotidiano, ao contrário, podem estar espalhados ou esparramados sucedendo todos os dias. Seus trabalhos resultam de pesquisa pessoal, da interação com outras crianças e com o entorno social e cultural ao qual estão expostas e que ao mesmo tempo constroem. Suas criações são registros, marcas históricas deixadas por elas desde pequeninas. Sintetizam e derivam de preocupações culturais, valores estéticos, modos de ver e estar no mundo. Esses desenhos e seus desenhistas procuram, sem dúvida, por vezes corresponder às demandas sociais que lhes interrogam e impõem jeitos de criar seus desenhos e de constituir-se frente ao mundo.

\section{Desenhos como produção e evidências de culturas entre as crianças e destas com os outros: criar, projetar e dar-se a ver}

Os desenhos criados por meninas e meninos coexistem com outras linguagens, alimentam-se delas e as nutrem ao mesmo tempo. Existem simultaneamente com diferentes maneiras de construir culturas e infâncias e, sem dúvida, das crianças construírem a si mesmas e dar se a conhecer. Menos ou mais tangíveis, intrigam a quem os olham, quando olham, no tempo sem tempo que temos e disponibilizamos (ou não) para a criançada.

0 uso do desenho em estudos, ligados, sobretudo à antropologia, tem ganhado destaque. Observa-se, mais recentemente, que os desenhos, assim como o ato de desenhar, tornaram-se não apenas instrumentos de coleta de dados, complemento do caderno de campo, mas também, e talvez mais fortemente, como forma de ver do próprio desenhista e do grupo ao qual ele pertence. Segundo o antropólogo português Joaquim Pais de Brito, desenha-se para ver, e se tem no desenho uma linguagem rica de oportunidades para se conhecer o que nos cerca (2009). Portanto, pode-se inferir que ao ver um desenho encontramos outra 
maneira de contar sobre o mundo, ou mundos. Recordando que cada imagem, em seu contexto social, implica e convida a variadas interpretações, vale levar em consideração em qual contexto e quais bagagens portamos para estar diante dos desenhos e vê-los. É imprescindível refletir sobre as formas de chegada e contato com esses traçados, aparentemente tão simples e desprovidos de complexidade.

Para compreender os arranjos organizados e apresentados pelas crianças nos desenhos é importante ver, acalmar, observar, escrever, observar e observar para então entrar em contato com essa manifestação expressiva. Não é explicar totalmente, uma vez considerando que estamos olhando de modo distanciado e isso incorre em descrições que resultam até mesmo de certo afastamento etário, mas entrar em contato deixando-se afetar pelas linhas, traçados, assuntos, formas, pela existência de outro modo explicativo que, ora vai ao nosso encontro, ora resiste e nos escapa, necessitando que outras portas de entrada sejam abertas. É bom esclarecer que não se pretende ser o porta-voz da infância apenas pelo fato de considerarmos suas manifestações expressivas como elementos das culturas. Trata-se sim, de procurar conhecê-la por ela e com ela. Essa perspectiva busca deixar aprender a partir e por outra cultura - sem esquecer-se que, dinâmica, ela se constitui nas relações entre todos -, neste caso, de crianças em suas sutilezas que enriquecem, mas que às vezes ficam subsumidas nas culturas reconhecidas no universo adulto. Um desafio: burilar o olhar.

\section{Ver vendo: desenhos e suas provocações}

Os desenhos e as reflexões apresentadas nesse ensaio resultam de pesquisa empreendida por mim há tempos (Gobbi, 1997) em que buscava-se conhecer a relação entre desenhos e o ato de desenhar e gênero. Polissêmicas, as imagens provocam que as visitemos por várias e várias vezes e de diferentes formas evocando lembranças, histórias, conhecimentos, sensações. Os desenhos de Fernando e Vitor aqui reproduzidos foram coletados numa escola de educação infantil da rede municipal de São Paulo. Ao longo de um ano de pesquisa, esses desenhos e o que foi exposto verbalmente pelos desenhistas provocaram a pensar, entre tantas coisas, sobre relações de gênero e familiares mantidas e construídas pelas crianças, bem como sobre o lugar e ponto de vista de meninos e meninas sobre essas questões. Vale informar que toda a turma era composta por 35 crianças que estavam em sua primeira experiência discente. Nessa pesquisa procurou-se considerar a oralidade conjugada ao desenho e o que se apresentava de modo visível ou invisível sobre o que se compreende como ser homem e mulher por crianças ainda tão pequenas. Partia-se do princípio de que era possível dialogar 
com as crianças sobre e a partir de seus desenhos, considerando-os como chaves que abrem portas ao diálogo e a um mundo de descobertas e tantos assuntos, desde que saibamos conduzir a conversa de forma a não determinar o que deve ser respondido, ou melhor, aquilo que se quer ouvir. Por vezes, o não dito, o não aparente em seus traços, esconde ou demonstra mais do que se pode supor.

\section{Figura 1: DESENHO ELABORADO POR FERNANDO}

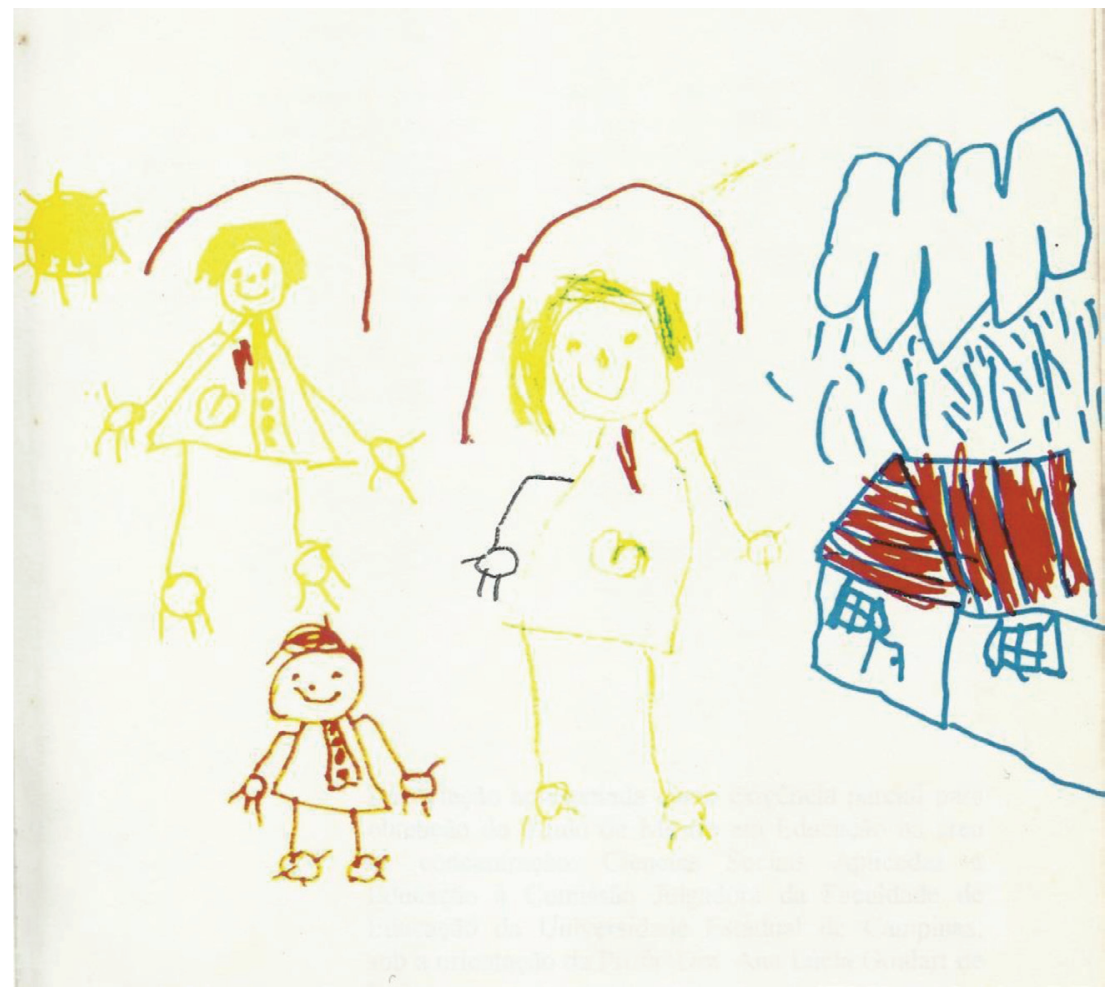

Fonte: Material empírico

A conjugação entre desenho e oralidade, em que a criança comenta sobre sua criação, apresenta-se como fecunda e capaz de revelar, em muitos momentos, como diversos grupos sociais compreendem a si e aos outros, ainda que saibamos o quanto reside de imaginação na composição das imagens. Em alguns casos, como é sabido, as crianças alteram as informações dadas sobre determinados desenhos, ainda assim, essa característica infantil não muda a perspectiva de compreensão deles como documento e artefato cultural. Na perspectiva em que conjugamos desenho e oralidade, a criança poderá falar sobre seus desenhos, narrando-os. Com isso possibilita ao outro que aprenda com as meninas e 
meninos, alimentando-se e aprendendo, também a partir de seu criador, sobre esta sua forma expressiva. Salienta-se que essa prática torna-se possível com crianças falantes, outro desafio encontra-se em conhecer aqueles criados pelas não falantes: os bebês, cujos traçados ainda são bastante negligenciados pelos adultos e pelas adultas.

Quanto à metodologia empregada para coletar os desenhos, compreendiase que o ato de desenhar apresenta e modifica certas lógicas de organização da infância em relação a distintas concepções, nesse caso de gênero, que até então se encontravam dormentes. A elaboração de desenhos suscitou conversas entre a pesquisadora e as crianças e entre elas sem a adulta, que reconfiguraram modos de perceber o outro - homem e mulher - ao mesmo tempo em que deram o tom para debate entre adultos e outras crianças. Conjugar desenho e oralidade como metodologia de trabalho constituiu-se como importante fonte de coleta de dados, ao mesmo tempo em que provia a investigação de formas de ver das crianças. Traçados e falas combinavam-se resultando em ricas manifestações infantis e descobertas ao longo da pesquisa.

No ato de desenhar, junto à sua turma na escola de educação infantil e sentado à mesa com outros colegas meninos, Fernando (criador do primeiro desenho aqui apresentadol ao utilizar o lápis vermelho para pintar partes de seu desenho, ouviu uma fala de contrariedade e repreensão proferida por um colega que estava ao seu lado: lápis vermelho é de mulherzinha! Pois é. Nas condições dadas à elaboração do desenho, a presença sedutora do lápis de cor vermelho, garantiu o uso pelo menino. Mas, o que estava contido na seleção da cor vermelha para se pintar uma imagem? Há muito mais elementos presentes no lápis vermelho do que apenas sua capacidade de colorir! Se, como nos ensina John Berger "o desenho de uma árvore não nos mostra uma árvore, mas uma árvore sendo olhada" $(2011)^{3}$ podese considerar que o lápis vermelho não mostra somente uma cor, mas uma cor sendo usada em determinado contexto social, cultural, econômico e oferecendo oportunidades para interpretações e apreensões diversas, segundo quem olha e quem cria.

A fala de um dos meninos ressoou transformando o ambiente de calmaria em campo de debates entre meninos e meninas, sobre o que é ser homem e ser mulher na sociedade brasileira. Tema caro a muitos de nós, bastante complexo, recheado de diversos pontos de vista, mas que ao surgir entre as crianças enquanto desenhavam e após, ao ver o resultado do desenho, sofre transformações e altera relações e modos de ver. 0 desenho dá a ver aquele que o faz e provoca que outros, ao redor, deem-se a ver. Suas opiniões, concepções mais ou menos arraigadas,

3. Tradução livre da língua espanhola pela qual me responsabilizo. 
apresentam-se a partir de uma representação posta em traçados e cores, em que o assunto, embora traga homem e mulher desenhados em dia de chuva - vemos a intenção nas linhas que saem das nuvens e certa cobertura sobre as cabeças de duas pessoas -, apresentam-se ainda mais fortemente quando faz circular entre todos a temática apresentada. Promove reorientações na composição do grupo, ao mesmo tempo em que provoca manifestações de todas as partes. Pode-se afirmar que quando presentes em distintos espaços eles modificam, transformando, não apenas espaço físico, mas aqueles que nele circulam. Deslocam o que se sabe sobre determinados assuntos e modos de vê-los. Conhecimentos e experiências das crianças e de todos ao redor, mais ou menos próximos, são evocados, mostrando-se.

Essas experiências das crianças que envolvem o ato de desenhar, além do ato de criação, evidente e instigante, dão a conhecer olhares mais atentos expressos a partir de investigações pessoais e coletivas de meninos e meninas, e, ainda interrogações e descobertas, nas relações com o outro, de modos de ver o outro. Reencontra-se o outro pelo desenho, esse outro que é capturado transformandose em traços, cores e formas diversas.

0 que tivemos nesse grupo de crianças foi um acontecimento. Acontecimento mobilizador em que se efetivou a ideia, segundo a qual, ver é concebido como ação do humano e desenhar como registro e exercício de vida. Diálogo por definição, o desenho fomentou trocas e mudanças de organização espacial, do grupo e das programações de diálogos e concepções sobre modos de ver de todos. Propôs, sem querer, uma sequência de ocorrências, com significados e pesos diversos que impulsionaram tomadas de posturas e elaboração de discursos, por vezes, inesperados. Algo aparentemente instantâneo ou efêmero - colorir um desenho com a cor vermelha - transmitiu-se de forma duradoura num registro de concepção de mundo. Deu a ver o gênero feminino e aspectos de sua construção social a partir de um menino com tão pouca idade. Mulherzinha. Trata-se de uma forma pejorativa de tratamento com que muitas mulheres eram chamadas, não sendo apenas o diminutivo da palavra mulher, está impregnado de valores, de concepções e formas de tratar e lidar com as mulheres. Volta-se a afirmar que na escolha da cor residem informações, modos de ver que traduzem e mostram elementos e aspectos presentes na sociedade. Pode-se assumir que algo similar ocorre quando, em situações de criação de desenhos, as crianças solicitam o chamado "lápis cor de pele" e, sem qualquer reflexão thes damos lápis bege, salmão, rosa-claro. 0 que está presente quanto às concepções étnicas e raciais no atendimento a esse pedido e no uso dessa cor? Dá o que pensar.

Reconfigura-se o olhar e o lugar ocupado no mundo. No que toca à questão de gênero mencionada, merece reflexão, pois implica tomada de posição. Nesse 
caso específico, o menino imediatamente tomou o lápis vermelho, retrucou o que havia sido dito pelo colega e pôs-se a pintar, rejeitando o que ouviu. 0 menino quase que se desenhava simultaneamente: resistência à imposição de gênero masculino para a qual em sua versão sexista, vermelho é coisa de mulher e, com isso, feminino pode ser, como foi historicamente ao longo de séculos, concebido como inferior ao masculino. Usar a cor aproxima-o dessa inferioridade e Fernando, ainda tão pequeno, resistiu a isso, ao seu modo. Não é, evidentemente, um militante organizado em sua intenção feminista, mas permite antever concepções diferentes sobre a questão. Sua tão sutil forma de resistência ao pegar o lápis e usá-lo, desafia outras tantas conversas e, quem sabe, mudanças de postura frente ao assunto. A presença do desenho e o ato de desenhar têm a capacidade de tirar do lugar certas convenções e jeitos prontos de olhar e conceber o mundo, como é possível inferir a partir da situação apresentada.

Em linha semelhante quanto à compreensão sobre a presença dos desenhos em diferentes grupos sociais e buscando com essa manifestação expressiva conhecer pontos de vista diversos, Simonetta Capecchi apresenta um projeto de recolha de desenhos, em especial nas cidades italianas, procurando o registro de impressões de diversos segmentos da população. 0 desenho, elaborado por todos de todas as idades, serve como ponto de partida para se conhecer o quê e como compreendem a cidade. Na cidade italiana de L'Aquila, após o terremoto de 2009, Capecchi cria uma "carriola di disegni" 4 , que funciona como um carrinho que passa a circular pela cidade convidando todos e todas a desenhar. Simbolicamente o que temos são tipos diferentes e importantes de construir e reconstruir memória, culturas e cidade. Um dos objetivos está em proporcionar e recolher desenhos de todos que estejam circulando pelas ruas, praças e demais espaços públicos, desde que queiram elaborar desenhos e registrar impressões sobre L'Aquila - vale lembrar o estado de calamidade e desconforto em que todos se encontravam devido ao desastre - e com isso não apenas circula pela cidade, como também, faz circular desenhos pela cidade, desenhos e pessoas autoras de seus traços, de suas marcas históricas, de desejos, de sonhos, que inventam e reinventam seus contextos sociais, históricos, culturais. 0 ritmo das ruas altera-se. Capecchi relaciona, em alguns momentos, a oralidade ao desenho e, com isso, garante a voz, talvez ainda não ouvida, faz falar e sentir a cidade em que todos estão circulando.

Ao associar elaboração de desenhos à fala daqueles que os produziram e de quem os veem, consegue ampliá-los e tê-los como chave de escuta e conversa para compreender, sob outros pontos de vista, aquilo que se pretendia registrar,

4. São carrinhos de mão que levam pela cidade materiais para se desenhar. Carriola di disegni é também nome do blog criado por Simonetta Capecchi em que são divulgados resultados desta e de outras pesquisas 
ou que foi capturado em diferentes contextos. 0 desenho se confirma como convite para que o outro olhe e, por que não, dialogue com quem vê o que foi criado?

No desenho de Victor, reproduzido a seguir, e que participou do grupo de crianças da mesma escola municipal de educação infantil com Fernando e outros tantos, mais possibilidades de compreensão encontram-se presentes. Vale salientar que a metodologia de recolha e proposta de desenhos procurava garantir que meninos e meninas tivessem acesso a folhas de desenho (nesse caso tamanho A4) comuns a essa escola de educação infantil, e observação direta enquanto as crianças elaboravam e discutiam sobre o que estavam desenhando. Vejamos.

Figura 2: DESENHO ELABORADO POR VICTOR

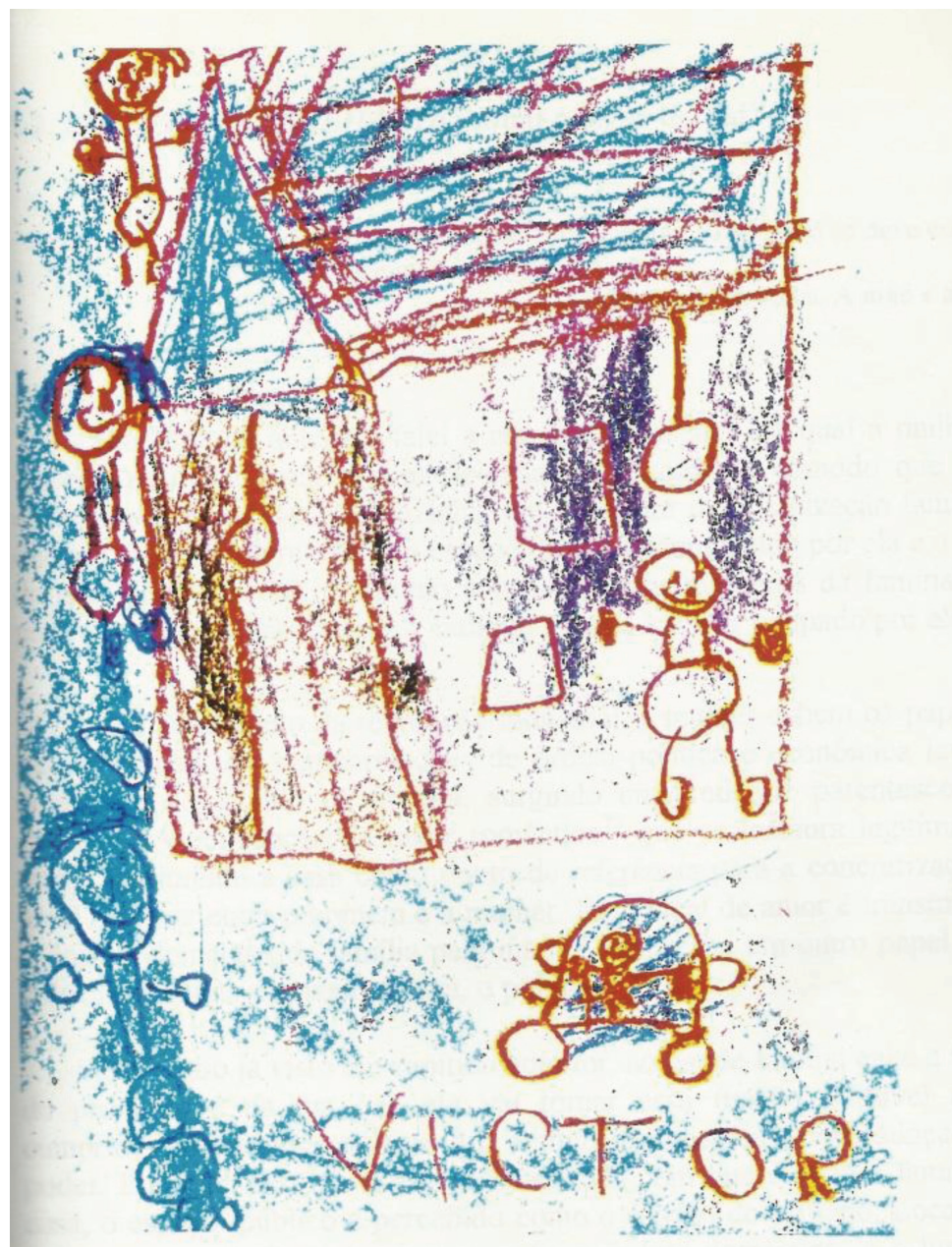

Fonte: Material empírico 
Como nossa capacidade de ver é construída socialmente, vale contextualizar sua produção e os modos de vê-la que são passíveis de questionamentos. Chamo a atenção para o desenho de Victor, pois o mesmo apresenta narrativa que leva à poética da vida cotidiana, essa não apenas percebida devido à presença diária do desenho, mas como registro de certa concepção e experiências estéticas das e pelas crianças. Destaco que na poética narrativa, presente nesse desenho, encontra-se parte de sua história, quase autobiográfica. Encerram-se nas imagens desenhadas fortes aspectos das ideias e observações infantis sobre as relações estabelecidas socialmente e, nesse caso, no interior da família do garoto desenhista.

Esse desenho liga-se aos lugares sociais ocupados pelo pai e pela mãe em casa e como Victor capta e apresenta essa relação, como ele dá a ver e, com isso, consente que se torne público esse momento familiar íntimo. Num dia, final de semana, bairro periférico da região noroeste paulistana, o pai sobe no telhado para consertá-lo. A mãe, dentro da casa, assiste a determinado programa de auditório bastante popular na televisão brasileira e transmitido aos domingos. Observe-se a solução dada pelo menino desenhista ao desejo de apresentar o pai subindo em direção ao telhado: ele desenha várias vezes o pai - do menor embaixo ao maior em cima já no telhado propriamente - escolhendo essa forma de apresentação como opção para se criar a noção do movimento de subir. Infere-se que não tendo como elaborar essa cena tridimensionalmente o faz de modo bidimensional, mas com saídas muito inventivas curiosamente usa a cor azul onde está o trajeto do pai até o telhado e vermelho para o lugar da casa em que está a mãe. Coincidência? Vale pensar sobre essa escolha.

Há um enredo visto sobre o papel que foi complementado pela fala do Victor. Sublinha-se que essa complementaridade não precisa ocorrer obrigatoriamente. Fala e desenhos podem coexistir ou não. 0 repertório arrolado nos diz de uma autêntica tarde de domingo, contudo, mais que isso, evidencia outro tempo que ganha forma a partir do estar na casa e todos os preparativos e rituais envolvidos nisso. Desenha vários elementos sobre o papel e de modo concomitante a subida ao telhado, mostra-nos o carro em que todos passearão posteriormente, como narrado por Victor. 0 automóvel coexiste às atividades do pai que está no carro ao mesmo tempo em que está no telhado. E a mãe? Dentro de casa a assistir TV. Repito que é possível, ao olhar atento, sensível e curioso observar e compreender diferentes aspectos existentes nessa relação familiar, organizada como familiar nuclear burguesa, comum a alguns de nós. Há o cotidiano presente que numa visão de perto podemos reconhecer e distanciando-se passamos a estranhá-la para, quem sabe, conhecer melhor.

Como já mencionado há muito nessa casa e na cena cotidiana que pode ser 
compreendido, e que contém em si, formas de atinar sobre a infância na periferia, sobre família percebida do ponto de vista de um menino, sobre um modo de vida de camadas mais pobres da cidade de São Paulo ou grandes centros urbanos, além, claro, de observarmos papéis femininos e masculinos desempenhados e vistos por uma criança, por um menino, com isso perguntando-nos sobre como são construídas e vividas as relações sociais na infância. 0 desenho - não obrigatoriamente conjugado à oralidade - são chaves que abrem possibilidades de descobertas sobre aqueles que os criaram. Neste caso, meninos que os elaboraram e que apresentavam ao longo do ato criador formas de pensar e representar cenas do cotidiano. Como representações e em seu caráter polissêmico, vale ponderar sobre o que está sendo visto e perscrutar traçados, cores, assuntos, ocupação do suporte desenhado, invenções.

\section{Os desenhos das crianças nos fazem pensar: de como não concluir e sair vendo e criando}

Procurou-se nesse ensaio suscitar conversas versadas sobre questões cruciais: a que e a quem servem os desenhos e, em especial, aqueles criados pelas crianças desde bem pequenas, como e por que existem? E, ainda mais, nos fazem existir ou pensar sobre eles. Por tempos deixamos de lado tudo o que fora criado por meninas e meninos, sobretudo quando ainda não tinham seis, sete anos de idade. Seus desenhos, então pouco notados, mas muito presentes entre nós, passavam por filtros que engessavam mais do que promoviam formas de ver em que os criadores apareciam em suas inteirezas. Ver, por vezes, implicava mensurá-los, colocando criatura e criador em lugares predeterminados impedindo-nos de observar e pensar sobre eles a partir do que nos apresentavam de diferentes pontos de vista.

A imagem nos convoca a pensar, parece-nos comum ouvir e repetir isso. Vale mais que mil palavras, ou ainda fala por si, independe de explicações ou demais relações. Falas que se tornaram comuns e presentes em nosso cotidiano. Contudo, quanto e de quais maneiras nos provoca a pensar quando são criadas por crianças? Buscou-se nesse ensaio chamar atenção para esse problema fazendo dos desenhos das crianças um fenômeno a ser compreendido a partir e com diferentes áreas do conhecimento, em destaque sociologia e antropologia. Suas contribuições fundamentam estudos em que desenhar é visto como documento e artefato cultural, forma de conhecer o outro e a si mesmo enquanto desenha enquanto desenhamos nos fazemos a nós mesmos - apresentar aspectos sociais e culturais e ser conhecido. Os desenhos das crianças, assim compreendidos, 
veiculam outras imagens e são carregadas de pensamentos, de modos de ver, sentir e estar no mundo. Sua existência move e organiza, não somente formas de pensar, como também lógicas explicativas. A presença de desenhos, seja no processo de sua feitura, como após ser criado, modificam o que estava ao redor. Debates, rejeições, burlar ou não o que fora imposto, ensejam questões entre as crianças e adultos envolvidos. Deslocam. Há mundos na ponta do lápis, e, quem sabe, podemos pensar que aprendemos a ver vendo e também desenhando, como num processo de apropriação do que está fora, para se conhecer por dentro aquilo que meninas e meninos, desde bem pequenos estão elaborando e, se estivermos atentos, mostrando-nos. Afinal para onde nos levam tantas linhas em traçados criados pela criançada? Vamos seguir, vaguear e aprender com eles.

\section{Referências}

BERGER, John. Sobre el dibujo. Barcelona: Editora Gustavo Gilli, 2011.

BRITO, Joaquim Pais de. (Org). Catálogo da exposição - desenhar para ver: o encontro de Bárbara Assis Pacheco com as galerias da Amazônia. Lisboa: Museu Nacional de Etnologia, 2009.

CAPECCHI, Simonetta. Una Carriola di disegni. Disponível em: <http:// unacarrioladidisegni.blogspot.com.br>. Acesso em: 20 maio 2013

GOBBI, Marcia Aparecida. Lápis Vermelho é de Mulherzinha: relações de gênero, crianças pequenas e educação infantil. 1997. 127 f. Dissertação (Mestrado em Educação)- Programa de Pós-Graduação em Educação, Unicamp,1997.

LUQUET, Georges Henri. El dibujo Infantil. Barcelona: Editorial Medica y técnica. 1981.

RICCI, Corrado. L'Arte dei Bambini. Bologna: Editora Nicola Zanicchelli, 1887.

SALAVISA, Eduardo. (Org.) Diários Gráficos em Almada. Almada. Câmara Municipal. Museu da Cidade, 2011. Disponível em:<issuu.com/gomadesign/docs/ diariosgraficos>. Acesso em: 20 maio 2013.

SOUZA, Carla Dameana. Lápices sin ponta: Imagens da infância e da adolescência na Guerra Civil Espanhola. Revista Domínios da Imagem, Londrina, Ano III, n. 5, p. 47-58, nov. 2009.

Recebido em julho de 2013 Aprovado em novembro de 2013

Marcia Aparecida Gobbi é doutora em Educação e professora da Faculdade de Educação da Universidade de São Paulo, Departamento de Metodologia de Ensino e Educação Comparada (EDM). E-mail: mgobbiausp.br 